meniscal extrusion and medial femoral cartilage showed a weak correlation with pain levels $(r=.254, p=.043 ; r=-.265, p=0.034$, respectively). Nevertheless, in the multivariate analysis after adjusting for age and BMI, both variables did not reach significance for explaining the differences in VAS levels. No association between the presence of synovial effusion and popliteal cyst and pain severity was found.

Conclusion: Plain radiography and ultrasonography reflect different structural changes in osteoarthritis that may play an important role in pain perception. Both imaging modalities can complement each other in order to improve the evaluation of the patient with KOA.

Acknowledgments: None

Disclosure of Interests: None declared

DOI: 10.1136/annrheumdis-2020-eular.2222

\section{AB0864 DO CORTICOSTEROIDS AND HYALURONIC ACID INJECTIONS CAUSE INFECTIONS? A SYSTEMATIC REVIEW OF LITERATURE ON ADVERSE EFFECTS AND INFECTION RATES OF INTRA- ARTICULAR CORTICOSTEROID AND HYALURONIC ACID INJECTIONS IN PATIENTS WITH KNEE OSTEOARTHRITIS}

C. Hatzantonis ${ }^{1}$. 'Luton and Dunstable Hospital, Trauma and Orthopaedics, Luton, United Kingdom

Background: Knee osteoarthritis has been a leading cause of chronic pain and disability in our increasingly aging population. Conservative management options of physiotherapy and oral analgesics offer some relief, but delivery of intra-articular injections such as corticosteroids or hyaluronic acid has increasingly become the mainstay of pain management of knee osteoarthritis. In a clinical setting, intra-articular injections offer a means to delay a total knee replacement. Despite the abundance of literature on corticosteroids and hyaluronic acid, there is no known percentage of infection rates or adverse effects that clinicians may use to inform patients prior to obtaining consent for the injection.

Objectives: To determine a rate of adverse events and infection rates in patients undergoing intra-articular injections of corticosteroids or hyaluronic acid.

Methods: A systematic review of current literature including studies involving patients ranging from 45 patients (Carmona L, 2018) to Cochrane reviews of 1767 patients (Campbell Kirk, 2015). From these studies, the number of patients, adverse reactions (i.e. pain, erythema) and serious adverse reactions (infections) were calculated.

Results: Within our study, there was a large variation of numbers of adverse effects of hyaluronic acid and corticosteroids amongst studies, with percentages as variable as $0-9.3 \%$. Corticosteroids demonstrated $11-26 \%$ reduction of adverse events compared to hyaluronic acid. However, confidence intervals were found to not be statistically significant.

Conclusion: Intra-articular injections of corticosteroids and hyaluronic acid, although deemed clinically effective, continue to demonstrate variable rates of adverse effects and infection amongst patients with progressive knee osteoarthritis. Disclosure of Interests: None declared

DOI: 10.1136/annrheumdis-2020-eular.5799

\section{AB0865 EPIDURITIS IN INFECTIOUS SPONDYLODISCITIS}

J. Mahbouba' ${ }^{1}$, O. Jomaa ${ }^{1}$, S. Zrour ${ }^{1}$, I. Bejia ${ }^{1}$, M. Touzi ${ }^{1}$, N. Bergaoui ${ }^{1}$ on behalf of Rheumatology Department. ${ }^{1}$ Hopital Fattouma Bourguiba, Rheumatology Department, Monastir, Tunisia

Background: The main problem with infectious spondylodiscitis (ISD) is the diagnosis difficulty. Tuberculosis, with deceptive clinical semiology, remains to date the most common cause in underdeveloped and developing countries.

Objectives: To report the frequency and characteristics of epiduritis in ISD and to specify its short and medium-term impact through a series of 70 cases. Methods: A descriptive retrospective study was conducted including patients with ISD, hospitalized in the rheumatology department at Fattouma bourguiba Hospital,Monastir TUNISIA between January 2009 and August 2019. Sociodemographic, clinico_biological and radiological data were collected.

Results: 34 male and 36 female were included. The average age was 53.91 \pm 15.3 years. The mean time to visit was $80.3 \pm 89$ days $[4,520]$. Co-morbidity was noted in $66.7 \%$ of patients: diabetes (22), hypertension (18), hemodialysis (8), heart disease (4), and long term corticosteroid therapy (4). Tuberculosis contagion was present in $7.2 \%$ of patients. The most frequent reason for consultation was low back pain (63.8\%) with a root syndrome in most patients $(>50 \%)$. Neurological abnormalities were noted in $8.7 \%$ of patients. Skin swelling was noted in $4.3 \%$ of patients. Biological inflammatory syndrome and hyperleukocytosis were the moost biological abnormalities reported respectively in $81.2 \%$ and $30.4 \%$ of patients,. Among 70 ISD: 29 were with common germ, 18 with tuberculosis, 8 with brucellosis, and 14 with an undetermined germ. $91.3 \%$ of patients underwent a spinal magnetic resonance imaging (MRI): epiduritis was documented in $72 \%$ of cases, frequently anterior (53\%). The epidural abscesses association was noted in 33 patients. It was pronounced mostly a the lumbar (19) and dorsal (14) levels. Epiduritis was frequently associated with para-vertebral soft tissues infiltration: pre-vertebral thickening (32), pre-vertebral collection (17), psoas muscle abscesses, (13). Spinal cord compression was noted in 2 patients. On 3-month visit, the ISD associated with epiduritis evolution was characterized by persistence of pain, hence radiological control was justified in 6 patients. A persistent biological inflammatory syndrome was noted in $27 \%$ of cases. Furthermore, 2 deaths were observed in this group of patients.

Conclusion: Epiduritis rate in ISD requires a well-codified diagnostic and therapeutic strategy that will consider carfelly the neurological prognosis involved. References: doi: 10.1155/2019/7413089.

doi: 10.1515/folmed-2016-0035

Acknowledgments: Rheumatology Department

Disclosure of Interests: None declared

DOI: 10.1136/annrheumdis-2020-eular.5890

\section{AB0866 1 THE PREVALENCE AND CLINICAL FEATURES OF FRAILTY SYNDROME IN PATIENTS WITH SYMPTOMATIC RADIOGRAPHIC KNEE OSTEOARTHRITIS AND RHEUMATOID ARTHRITIS: A STUDY OF THE KOREAN NATIONAL HEALTH AND NUTRITION EXAMINATION SURVEY (KNHANES)}

S. H. Joo ${ }^{1,2}$, J. Lee ${ }^{3}$, Y. W. Song ${ }^{4,5} .{ }^{1}$ College of Medicine, Pusan National University, Department of Microbiology and Immunology, Yangsan, Korea, Rep. of (South Korea); ${ }^{2}$ Bethesda hospital, Departement of Internal Medicine, Yangsan, Korea, Rep. of (South Korea); ${ }^{3}$ Inha University Hospital, Prevention and Management Center, Incheon, Korea, Rep. of (South Korea); ${ }^{4}$ Seoul National University Hospital, Seoul, Korea, Rep. of (South Korea); ${ }^{5}$ Graduate School of Convergence Science and Technology, and College of Medicine, Medical Research Center, Seoul National University, Department of Molecular Medicine and Biopharmaceutical Sciences, Seoul, Korea, Rep. of (South Korea)

Background: Frailty is defined as syndrome of physical decline in late life, characterized by marked vulnerability to adverse health outcomes. Knee osteoarthritis $(\mathrm{OA})$ could be one of the major diseases related to frailty conditions. The prevalence and clinical features of frailty syndrome in knee OA and rheumatoid arthritis (RA) were not reported previously.

Objectives: We studied the clinical features and nutritional status of knee $\mathrm{OA}$ and RA patients with frailty syndrome in nationwide survey data

Methods: Symptomatic knee osteoarthritis patients were defined who had knee joint pain accompanied with grade 2 or more Kellgren-Lawrence score in plain radiographic studies from the data of KNHANES $(\mathrm{N}=17,873$, from 2010 to 2013). RA was defined who diagnosed by physician. We calculated the frailty index (score 0 1.0) using 46 items from the frailty related co-morbidities and laboratory abnormalities according to Rockwood clinical frailty scale. We analyzed the clinical features of three frailty groups [robust $(\leq 0.10)$, pre-frail $(0.1<$ $\left.{ }^{*} \leq 0.21\right)$, and frail $(>0.21)$ in symptomatic radiographic knee OA patients and RA patients.

Results: The prevalence of Knee OA patients was $8.59 \%$ [95\% Cl: 8.19-9.01]. Relative risk ratio is significantly increased in pre-frail (OA; 2.66 [2.26-3.14], RA;4.02 [3.07-5.27]) and frail group (OA; 6.27 [5.20-7.57], RA;7.00[5.03-9.74]) in polytomous logistic regression.

Body mass index (BMI), white blood cell, platelet, and serum creatinine were significantly increased in knee OA and RA patients with frailty syndrome. But, hemoglobin, estimated GFR (CKD-EPI equation) and EQ-5D were significantly decreased in knee OA and RA patients with frailty syndrome (Table). The daily nutritional intakes of total calories, carbohydrate, protein, fat, sodium and potassium were significantly decreased in knee OA patients with the frailty syndrome. In RA patients, the significant decreased nutritional intakes of total calories, carbohydrate, protein and fat were observed.

Conclusion: We showed increased $\mathrm{BMI}$, decreased renal function and lowe nutritional status in symptomatic radiographic knee OA and RA patients with frailty syndrome. 
Table.

\begin{tabular}{|c|c|c|c|c|c|}
\hline & & Robust & Pre-frail & Frail & p \\
\hline \multirow[t]{2}{*}{$\begin{array}{l}\text { Body mass } \\
\text { index }\left(\mathrm{kg} / \mathrm{m}^{2}\right)\end{array}$} & Knee OA & $\begin{array}{c}24.13 \\
{[23.74-24.53]}\end{array}$ & $\begin{array}{c}25.07 \\
{[24.83-25.32]}\end{array}$ & $\begin{array}{c}25.46 \\
{[25.14-25.78]}\end{array}$ & $<0.0001$ \\
\hline & RA & $23.73[23.04-24.42]$ & $\begin{array}{c}23.58 \\
{[23.20-23.97]}\end{array}$ & $\begin{array}{c}24.97 \\
{[24.28-25.66]}\end{array}$ & 0.001 \\
\hline \multirow[t]{2}{*}{$\begin{array}{l}\text { Hemoglobin, } \\
\text { g/dL }\end{array}$} & Knee OA & $\begin{array}{c}13.53 \\
{[13.36-13.70]}\end{array}$ & $\begin{array}{c}13.51 \\
{[13.42-13.61]}\end{array}$ & $\begin{array}{c}13.27 \\
{[13.14-13.40]}\end{array}$ & 0.004 \\
\hline & RA & $13.63[13.34-13.92$ & $\begin{array}{c}13.30 \\
{[13.14-13.46]}\end{array}$ & $\begin{array}{c}13.15 \\
{[12.85-13.45]}\end{array}$ & 0.060 \\
\hline \multirow[t]{2}{*}{$\begin{array}{l}\text { White blood cell, } \\
10^{3} / \mu \mathrm{L}\end{array}$} & Knee OA & $5.50[5.29-5.71]$ & $5.94[5.81-6.07]$ & 6.41 [6.24-6.58] & ]$<0.0001$ \\
\hline & RA & 5.47 [5.13-5.82] & $5.85[5.64-6.06]$ & 6.68 [6.32-7.03] & $<0.0001$ \\
\hline \multirow[t]{2}{*}{ Platelet, $10^{3} / \mu \mathrm{L}$} & Knee OA & $\begin{array}{c}246.03 \\
{[238.52-253.53]}\end{array}$ & $\begin{array}{c}258.13 \\
{[253.44-262.82]}\end{array}$ & $\begin{array}{c}259.96 \\
{[253.40-266.53]}\end{array}$ & 0.045 \\
\hline & RA & $\begin{array}{c}237.49 \\
{[222.91-252.06]}\end{array}$ & $\begin{array}{c}255.30 \\
{[247.50-263.10]}\end{array}$ & $\begin{array}{c}262.04 \\
{[248.32-275.77]}\end{array}$ & 0.038 \\
\hline \multirow[t]{2}{*}{$\begin{array}{l}\text { Serum creati- } \\
\text { nine, } \mathrm{mg} / \mathrm{dL}\end{array}$} & Knee OA & $\begin{array}{c}0.734 \\
{[0.712-0.756]}\end{array}$ & $\begin{array}{c}0.764 \\
{[0.751-0.777]}\end{array}$ & $\begin{array}{c}0.861 \\
{[0.826-0.895]}\end{array}$ & $<0.0001$ \\
\hline & RA & $\begin{array}{c}0.732 \\
{[0.686-0.779]}\end{array}$ & $\begin{array}{c}0.783 \\
{[0.762-0.805]}\end{array}$ & $\begin{array}{c}0.917 \\
{[0.840-0.994]}\end{array}$ & $<0.0001$ \\
\hline \multirow[t]{2}{*}{$\begin{array}{l}\text { CKD-EPI eGFR, } \\
\mathrm{ml} / \mathrm{min}\end{array}$} & Knee OA & $\begin{array}{c}88.54 \\
{[86.77-90.31]}\end{array}$ & $\begin{array}{c}83.89 \\
{[82.89-84.88]}\end{array}$ & $\begin{array}{c}76.22 \\
{[74.80-77.63]}\end{array}$ & $<0.0001$ \\
\hline & RA & 94.30 [90.77-97.82] & $\begin{array}{c}85.86 \\
{[84.00-87.73]}\end{array}$ & $\begin{array}{c}74.76 \\
{[70.91-78.61]}\end{array}$ & $<0.0001$ \\
\hline \multirow[t]{2}{*}{ EQ-5D } & Knee OA & $\begin{array}{c}0.933 \\
{[0.921-0.944]}\end{array}$ & $\begin{array}{c}0.804 \\
{[0.793-0.815]}\end{array}$ & $\begin{array}{c}0.635 \\
{[0.616-0.653]}\end{array}$ & $<0.0001$ \\
\hline & RA & $\begin{array}{c}0.966 \\
{[0.953-0.979]}\end{array}$ & $\begin{array}{c}0.857 \\
{[0.839-0.874]}\end{array}$ & $\begin{array}{c}0.666[0.619 \\
-0.713]\end{array}$ & $<0.0001$ \\
\hline
\end{tabular}

Acknowledgments: None

Disclosure of Interests: None declared

DOI: 10.1136/annrheumdis-2020-eular.5182

\section{AB0867 INCREASED ADIPONECTIN LEVELS ARE ASSOCIATED WITH HIGHER RADIOGRAPHIC SCORES IN THE KNEE JOINT, BUT NOT IN THE HAND JOINT: THE DONG-GU STUDY}

J. H. Kang ${ }^{1}$, S. E. Choi ${ }^{1}$, H. Xu ${ }^{1}$, D. J. Park', S. S. Lee ${ }^{1}{ }^{1}$ Chonnam National University Medical School \& Hospital, Gwangju, Korea, Rep. of (South Korea)

Background: Several studies have evaluated the association between serum adiponectin levels and knee and hand osteoarthritis (OA), with mixed results.

Objectives: The aim of this study was to investigate the relationship between $\mathrm{OA}$ and serum adiponectin levels according to the radiographic features of knee and hand $\mathrm{OA}$.

Methods: A total of 2,402 subjects were recruited from the Dong-gu Study. Baseline characteristics were collected via a questionnaire, and X-rays of knee and hand joints were scored by a semi-quantitative grading system. The relationship between serum adiponectin levels and radiographic severity was evaluated by linear regression analysis.

Results: Subjects with higher tertiles of serum adiponectin were older and had a lower body mass index than those with lower tertiles. In the knee joint scores, serum adiponectin levels were positively associated with the total score $(P<0.001)$, osteophyte score $(P=0.003)$, and joint space narrowing (JSN) score $(P<0.001)$ among the three tertiles after adjustment for age, sex, body mass index, smoking, alcohol consumption, education, and physical activity. In the hand joint scores, no association was found between serum adiponectin levels and the total score, osteophyte score, JSN score, subchondral cyst score, sclerosis score, erosion score, and malalignment score among the three tertiles after adjustment.

Conclusion: In this study, we found that increased adiponectin levels were associated with higher radiographic scores in the knee joint, but not in the hand joint, suggesting different pathophysiologic mechanisms in the development of OA.

Disclosure of Interests: None declared

DOI: 10.1136/annrheumdis-2020-eular.1677

\section{AB0868 \\ EFFICACY AND SAFETY OF PULSED ELECTROMAGNETIC FIELDS IN THE TREATMENT OF OSTEOARTHRITIS: RESULTS OF A MULTICENTER BLIND PLACEBO-CONTROLLED STUDY.}

A. Karateev ${ }^{1}$, E. Pogozheva ${ }^{1}$, M. Sukhareva ${ }^{2}$, A. Lila ${ }^{2} .{ }^{1}$ Nasonova Research Institute of Rheumatology, Moscow, Russian Federation; ${ }^{2}$ Nasonova Research Institute of Rheumatology, Moscow, Russian Federation

Background: Pulsed electromagnetic fields (PEMF) is a well - known method of non-pharmacological treatment that is widely used in knee osteoarthritis (KOA). Objectives: To evaluate the effectiveness and safety of PEMF in KOA.

Methods: The study group consisted of $231 \mathrm{KOA}$ patients, $77.9 \%$ of women, age $61.9 \pm 12.2$ years, BMI $30.6 \pm 5.8 \mathrm{~kg} / \mathrm{m} 2$, average disease duration 5.0 [2.0;10.0] years. Patients were randomly assigned to two groups. Group 1 patients received PEMF for 14 days using a device that creates a low-frequency pulsed magnetic field, group 2-a false PEMF (a device that completely simulates a working device, but does not create a magnetic field). We evaluated the dynamics of the WOMAC index, the severity of pain at rest and when moving on a $100-\mathrm{mm}$ visual analog scale (VAS), the need for non-steroidal anti-inflammatory drugs (NSAIDs), and the evaluation of the patient's treatment result (on a 5-point scale).

Results: Statistically significant reduction in pain, stiffness, and improved function was observed in both true PEMF and false PEMF. Thus, the WOMAC pain in Group 1 decreased from 231 [180; 290] to 110 [60; 166.3], p<0.001; in Group 2 from 212.4 $[145 ; 260]$ to $143[76.5 ; 200], p<0.001$, the severity of pain in rest (VAS) decreased in Group 1 from 47 [27.8; 60] to $20[10 ; 30], p<0.001$; in Group 2 from 40 [20; 57.5] to 20 [7.5; 40], p<0.001. After therapy, the need for NSAIDs also decreased: in Group 1 NSAIDs were canceled or reduced in $33.1 \%$ of patients, in Group 2 - in $16.8 \%$ $(p=0.006)$. For all indicators, the dynamics were statistically more significant in Group 1 than in Group 2. The result of treatment as "good" and "excellent" was evaluated by $58.5 \%$ of patients in Group 1 and $39.8 \%$ of patients in Group 2, $p<0.001$. No serious adverse reactions were observed when using true and false PEMF. Two patients who received false PEMF therapy was interrupted due to increased joint pain.

Conclusion: PEMF with short-term use provides a significant improvement in the condition of KOA patients. PEMF is well tolerated and does not cause serious complications.

Disclosure of Interests: None declared

DOI: 10.1136/annrheumdis-2020-eular.3973

\section{AB0869 CLINICAL FEATURES OF WOMEN WITH KNEE OSTEOARTHRITIS AT DIAGNOSIS IN CAMEROON, SUB-SAHARAN AFRICA}

F. Kemta Lekpa ${ }^{1,2}$, A. Tidjong Kamkui ${ }^{3}$, H. Namme Luma ${ }^{3}$, S. P. Choukem ${ }^{1,2}$ ${ }^{1}$ Douala General Hospital, Internal Medicine, Douala, Cameroon; ${ }^{2}$ University of Dschang, Faculty of Medicine, Dschang, Cameroon; ${ }^{3}$ Douala General Hospital, Douala, Cameroon

Background: To the best of our knowledge, no study has been done in sub-Saharan Africa among those who suggest that knee osteoarthritis is more severe in women.

Objectives: To assess differences in features of knee osteoarthritis between female and male patients in a sub-Saharan Cameroonian population.

Methods: A cross-sectional study from December 2018 to April 2019 conducted in the Rheumatology Unit of the General Hospital, Douala, Cameroon. We included patients with a recent diagnosis of knee osteoarthritis according to 1986 ACR criteria and Kellgren-Lawrence radiographic grading $\geq 2$. Sociodemographic, clinical, radiographic and therapeutic data at diagnosis were collected. Assessment of the functional disability was done using the Lequesne algofunctional index more adapted to Africans than WOMAC index. We compared these data between women and men. A $p<0.05$ was considered to be statistically significant.

Results: We screened 168 patients with the diagnosis of knee osteoarthritis. Seventeen patients with Kellgren-Lawrence radiographic grading at 1 were excluded. Then, we included 151 patients (120 women and $31 \mathrm{men}$ ) in the final analysis. The main characteristics of patients at diagnosis are summarized in Table 1. Knee osteoarthritis in women was characterized by a low level of education, a low financial income, and a high frequency of obesity. There was no difference between women and men for age at diagnosis, place of residence, intensity of pain, functional disability, number of compartments of the affected knee, Kellgren-Lawrence radiographic grading, and treatment previously received. 